\title{
Investigation of Biodegradation Speed and Biodegradability of Polyethylene and Manihot Esculenta Starch Blends
}

\author{
Abiodun A. Abioye ${ }^{1 *}$, Chukwunonso Obuekwe ${ }^{1}$, Oluwatosin Fasanmi ${ }^{1}$, \\ Oreofe Oluwadare², Oluwabunmi P. Abioye', Sunday A. Afolalu', \\ Stephen A. Akinlabi ${ }^{3}$, Christian A. Bolu \\ 1 Department of Mechanical Engineering, Covenant University, Cannanland, Ota. Nigeria \\ 2 PASAD Research Innovation Nigeria (PRIN), Lagos. Nigeria \\ 3 Department of Mechanical \& Industrial Engineering, University of Johannesburg, South Africa \\ * Corresponding author's e-mail: abiodun.abioye1@covenantuniversity.edu.ng
}

\begin{abstract}
Over 350 million tons of conventional plastics are currently produced from petroleum per year and this amount is expected to rise exponentially in the near future. Proper disposal of these products has caused a great problem for the waste management industry and as a result, there is a significant negative impact on the environment. As a matter of fact, in order to reduce the environmental impact of plastics, some products obtained from agriculture (like starch) are used as polymer blend with synthetic plastics. This study shows that Manihot esculenta can be blended with polyethylene to form a partially degradable polymer. The processing conditions and sample formulations are shown to significantly affect the structure of the polymer which has a concomitant effect upon the degradation ratio as well as the degradation rate. Six samples were produced by varying composition of the blend between Low-density Polyethylene and Manihot esculenta using glycerol and water as plasticiser. These samples were buried in soil and the degradation ratios and rates were studied within a period of 28 days. The results showed that these produced biopolymers are environmentally compatible and bio-degradable. The rate of biodegradation in soil of these biopolymer samples varied largely. The polymer blend with $80 \%$ LDPE (20 CaS) by weight had the most regular weight loss over the period of the study. Under the conditions the study was carried out, polymer blend $20 \mathrm{CaS}$ also had the steadiest rate of degradation. Hence, 80\% LDPE (wt.\%) blended with Manihot esculenta starch is the optimal ratio with regard to the degradability of biopolymer in sandy-loam soil.
\end{abstract}

Keywords: degradation rate, degradation ratio, biodegradable, polymer, manihot esculenta

\section{INTRODUCTION}

Almost 10 percent (by weight) of municipal garbage content are plastics (D'Alessandro, 2014). This is because recently, there has been an exponential increase in the use of polymer in modern society. The inappropriate control of the resulting waste caused its accumulation and led to environmental pollution. In contrast to the materials in widespread use since the onset of the $20^{\text {th }}$ century; like aluminium, glass, iron and paper; plastics have a low retrieval rate. Thus, they are problematic to reuse or recycle considering that they constitute complex composites having varying levels of contamination - by food and other biological substances (Hopewell et al, 2009). Unrecycled plastics end up accumulating and sitting in landfills for hundreds, even thousands of years without decomposing. Synthetic plastics do not degrade; they usually just break up into a multitude of smaller bits such so that the pieces from a one-litre bottle could end up on every mile of beach throughout the world (Barnes et al, 2009; Gregory, 2009). These plastics in landfills and the environment; discharge toxic pollutants (Gilpin et al, 2003) which contaminate groundwater and soil; cause changes in the carbon dioxide $\left(\mathrm{CO}_{2}\right)$ cycle; some plastics like Styrofoam (foamed polystyrene) bring about a release of neurotoxins at high doses when temperatures increase (West- 
blad et al, 2002). Plastic bags, bottles, films, and other polymeric materials clog drainage systems causing flooding in third world countries. Wildlife might also ingest plastic matter, often leading to intestinal blockage and inherently death (Sigler, 2014; Derraik, 2002).

Despite these challenges, in the last fifty years, the production of plastic has reached enormous levels. The industries in developing countries continue to make use of non-degradable polymeric materials for packaging and bottling of products because they cannot afford the cost of degradable polymers. According to Stevens (2002), about two hundred billion pounds of plastic were manufactured in the world per year as at 2002. This is equivalent to about forty pounds of plastic per person, in a year. Also, between thirty and forty-two percent of plastic produced is used for packaging. Out of the plastic produced, more than sixty billion tons are thrown away every year in the United States (Stevens, 2002). The plastics derived from petroleum are made from synthetic polymers. However, polymer chains are also found in nature. These chains are common in cellulose, lignin, and starch (Farrin, 2005). Starch is one of the most common and easily obtained natural polymers, making it attractive as a potential bio-based alternative to synthetic polymers (Wroblewska-Krepsztul et al, 2018; Johnsson and Steuer, 2018; Garrison et al, 2016; Abbott et al, 2014). Africa is known for the large production of Manihot esculenta, Nigeria is the largest producer with about 45 million metric tonnes/year (Akinpelu et al, 2011; FAO, 2008; Egesi et al, 2006). Manihot esculenta starch is a cheap and easily obtainable natural polymer that could be blended with synthetic polymer to enhance degradation. Several researchers (Mostafa et al, 2018; Makhtar et al, 2013; Cho et al, 2011) carried out the studies on the production and analysis of biodegradable polymers as well as their impact on the environment. Plastics are typically organic polymers of high molecular mass, most commonly derived from petrochemicals thus making them synthetic (Andrej, 2012). Conversely a range of variants are made from renewable stock such as Polylactic acid from corn or Cellulosics from cotton linters (Mostafa et al, 2018; Axel, 2009). People have been utilizing naturally derived plastics for far longer than one might envision. For instance, medieval artisans made lantern windows from translucent slices of animal horn, which is composed of keratin - a blended carbon-nitrogen polymer - a similar material that skin and hair, as well as fleece, is made of (Nobert, 1968).

This research produced polymer blend samples from LDPE and Manihot esculenta starch at different compositions and involved the analysis of their biodegradation ratio and rate over the period of 28 days with the view of determining the composition blend that gave optimum biodegradation properties.

\section{MATERIALS AND METHODS}

\section{Materials and Apparatus}

Over $10 \mathrm{~kg}$ of Low-Density Polyethylene (LDPE) was sourced for this research. The starch used in this project was made from Manihot esculenta. Glycerol was used as the plasticizer. Other materials used include distilled water, paper tape and thread. Iron sponges and detergents were used as cleaning materials.

The apparatus included a crucible furnace, stirrer, the OHAUS digital weighing scale (Model PA214), two stainless steel wire mesh sieves (Ø $0.08 \mathrm{~mm} / 80 \mu \mathrm{m}$ and $\varnothing 0.2 \mathrm{~mm} / 200 \mu \mathrm{m}$ ), Winkworth Z Blade Sigma industrial blender, beakers, plastic bottles, cutter, trays and aluminium foil sheets.

\section{Starch extraction process}

The Manihot esculenta tubers were thoroughly washed and cleaned to remove dirt. The peeled roots were sliced and then ground with the Winkworth Z Blade Sigma industrial blender for 5 minutes to produce a smooth mash. The mash was then introduced into a starch extractor. The supernatant liquid was drained away and the paste was dewatered to reduce the moisture content. The $200 \mu \mathrm{m}$ wire mesh sieve was used to separate starch milk from the solid fibrous residue. The starch milk was then heated in an oven to obtain the dry powdered starch which was further sifted to obtain micrometre sized particles using the $80 \mu \mathrm{m}$ wire mesh sieve. At the end of the process, about twenty-five percent $(25 \%)$ starch by weight was obtained from the mature Manihot esculenta tubers. This procedure was based on the methodology of Leonel (2007) and Ladeira et al (2013) shown in Figure 1. 


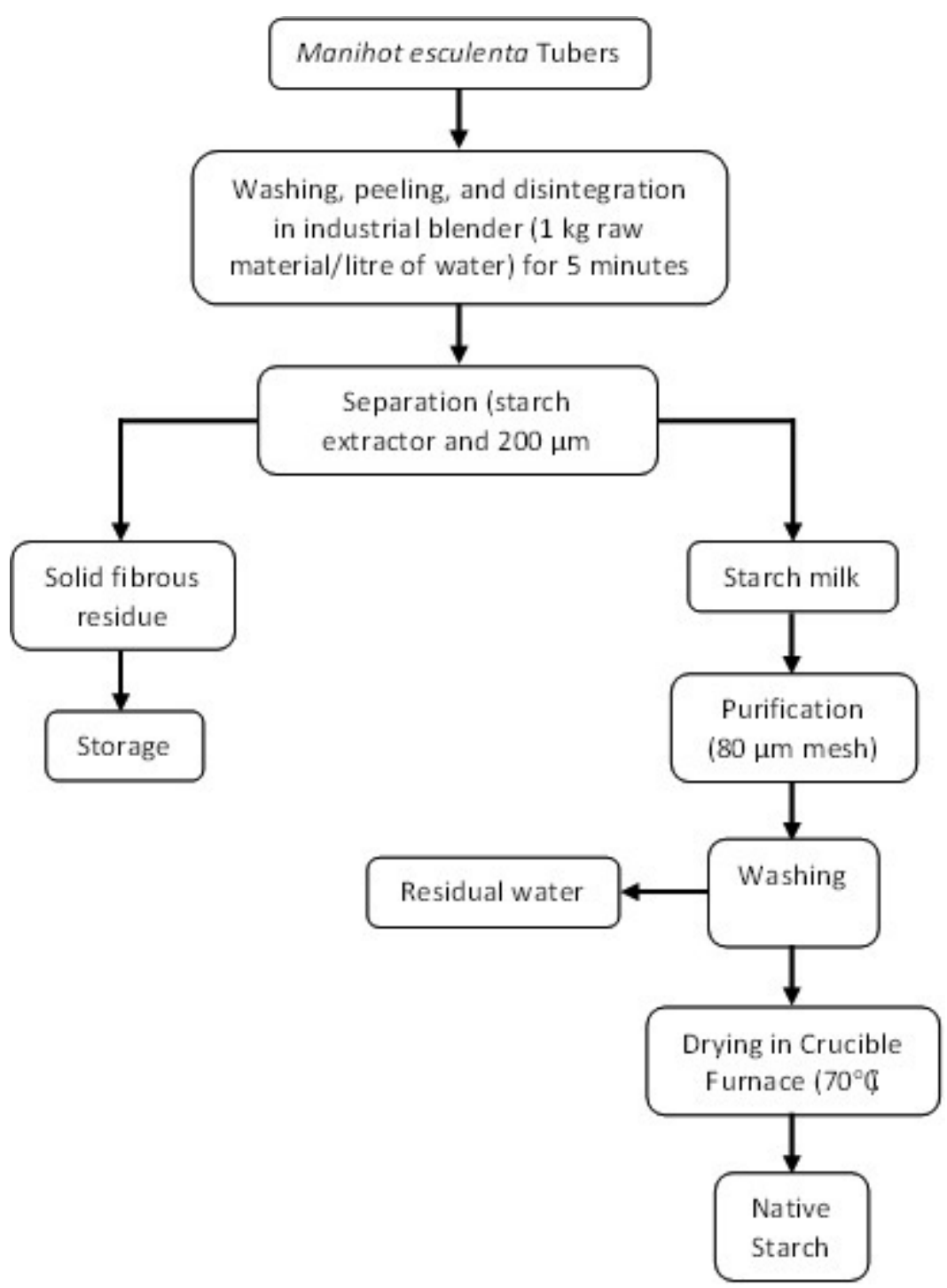

Figure 1. Flow Chart for Manihot esculenta Starch Production

\section{Plastic Blend Production}

One percent $(1 \%)$ concentration of glycerol was produced by diluting $10 \mathrm{ml}$ of pure glycerol with $1000 \mathrm{ml}$ of distilled water as plasticizer. The crucibles were prepared by coating them with coconut oil to avoid sticking of the polymer blend to the surface of the crucibles. A total of 6 sample blends containing 5\%,10\%, 15\%, 20\%, $40 \%$ and $50 \%$ by weight of Manihot esculenta starch was prepared by weighing LDPE and the prepared starch using the OHAUS digital weighing scale (Model PA214). The weighed LDPE and starch were mixed with the glycerol (plasticizer) for each percentage composition, as shown in Table 1. These mixtures were poured into the prepared crucible and allowed to melt and blend properly by mechanical stirring at the temperatures above $120^{\circ} \mathrm{C}$. The molten polymer blends were then poured on aluminium foil and allowed to cure at room temperature $\left(25^{\circ} \mathrm{C}\right)$ for 24 hours. This procedure was repeated for all 6 blend formulations. A pure LDPE sample (i.e. 100\% LDPE) which served as the control sample was also prepared. Each produced polymer blend was weighed using the OHAUS digital weighing scale (Model PA214) to determine the initial weight.

\section{Biodegradation Analysis}

The weighed samples were buried in sandy loam soil at a depth of about $10.16 \mathrm{~cm}$ (4 in.) for a period of 28 days in an uncontrolled environment. The biodegradation of the polymer blend samples was monitored by excavating them from the soil every seven days for a period of four weeks and the degradation was calculated by measuring the weight loss per week using equation 1 . This 
Table 1. LDPE/Manihot esculenta starch formulations

\begin{tabular}{|c|c|c|}
\hline Sample name & LDPE (wt.\%) & $\begin{array}{c}\text { Manihot esculenta Starch } \\
\text { (wt.\%) }\end{array}$ \\
\hline $5 \mathrm{CaS}$ & 95 & 5 \\
\hline $10 \mathrm{CaS}$ & 90 & 10 \\
\hline $15 \mathrm{CaS}$ & 85 & 15 \\
\hline $20 \mathrm{CaS}$ & 80 & 20 \\
\hline $40 \mathrm{CaS}$ & 60 & 40 \\
\hline $50 \mathrm{CaS}$ & 50 & 50 \\
\hline
\end{tabular}

method is commonly known as "degradation by weight loss" (Maryam and Hadi, 2016; Mahalakshmi and Andrew, 2012; Dong et al, 2008; Yang et al, 2006). This procedure was repeated for all the produced samples for this period of time:

$$
D=\frac{w_{0}-w_{1}}{w_{0}} \times 100 \%
$$

where: $D=$ Degradation Ratio (\%)

$$
\begin{aligned}
& w_{0}=\text { initial weight }(\mathrm{g}) \\
& w_{1}=\text { current weight }(\mathrm{g})
\end{aligned}
$$

The degradation rate was determined using equations 2 and 3 for all the buried samples for the given period. The degradation rate was calculated by finding the instantaneous degradation ratios as follows:

$$
\begin{gathered}
D_{i}=\frac{w_{x}-w_{y}}{w_{x}} \times 100 \% \\
\mathrm{D}_{\mathrm{t}}=\frac{\mathrm{D}_{\mathrm{i}}}{\mathrm{N}}
\end{gathered}
$$

where: $D_{i}=$ Instantaneous Degradation Ratios

$D_{\mathrm{t}}=$ Degradation Rate (\% per day)

$N=$ Number of days

\section{RESULTS AND DISCUSSIONS}

The results of the biodegradation ratio and biodegradation rates for the $6 \mathrm{LDPE} /$ Manihot esculenta blends are shown in Figures 2 to 8 .

Figure 2 shows a very slow but relatively steady increase in the weekly degradation ratio for sample $5 \mathrm{CaS}$ degrading by $1.35 \%$ after 7 days and then finally by $2.74 \%$ after 28 days. Conversely, the degradation rate for $5 \mathrm{CaS}$ exhibited a decline from $0.19 \%$ per day during the first week to $0.10 \%$ per day during the second week, then $0.05 \%$ the third week and slightly increasing to $0.06 \%$ in the final week.
For sample $10 \mathrm{CaS}$, Figure 3 shows that the degradation ratio also increased slowly; $1.42 \%$, $1.53 \%, 1.61 \%$ and $2.50 \%$ after the first, second, third and fourth weeks respectively. However, the values obtained for the degradation rate was very low and slightly erratic. A decrease in degradation rate per day for the first $(0.20 \%)$ and second $(0.02 \%)$ weeks was observed; then, an increase for the third $(0.01 \%)$ and fourth $(0.13 \%)$ weeks was noted.

According to the plot in Figure 4, sample $15 \mathrm{CaS}$ showed significantly higher values for degradation ratio: $5.66 \%$ for the first week, $7.56 \%$ the second week, $7.83 \%$ the third and finally $9.78 \%$ after 28 days. The degradation rate for $15 \mathrm{CaS}$ followed a similar pattern to $10 \mathrm{CaS}$; $0.81 \%, 0.29 \%, 0.04 \%$ and $0.30 \%$ after the first to fourth weeks, respectively.

In Figure 5, it can be seen that $4.15 \%$ of sample $20 \mathrm{CaS}$ degraded by the end of the first week, $8.07 \%$ by the second, $12.98 \%$ by the third and finally $18.66 \%$ by the end of the fourth week. This is a very steady and significant amount of degradation over 28 days. Average degradation rates per day were also rather steady over the period of study: $0.59 \%, 0.58 \%, 0.76 \%$ and $0.93 \%$ per day for the first to fourth weeks, respectively.

The degradation ratios and rates for sample $40 \mathrm{CaS}$ were represented in the chart in Figure 6. $18.73 \%$ of the sample had degraded by the end of the first week. Then, this value increased greatly to $75.05 \%$ by the second week. For the third (76.57\%) and fourth (78.05\%) weeks, the degradation ratios did not see further significant increase. The degradation rate per day during the first week was $2.68 \%$, then increased rapidly to $9.90 \%$ during the second week. A sharp decrease to $0.87 \%$ was then recorded during the third week and then $0.91 \%$ was recorded for the fourth and final week.

It can be seen from Figure 7 that the degradation ratio of sample $50 \mathrm{CaS}$ had an increasing pattern similar to that of sample $40 \mathrm{CaS}, 27.00 \%$ after first week then $45.53 \%, 45.79 \%$ and $45.85 \%$ after the second, third and fourth week respectively. The degradation rate per day during the first week was $3.86 \%, 3.63 \%$ during the second week, then $0.07 \%$ during the third week and $0.02 \%$ during the fourth week.

Figure 8 shows a positive linear relationship between the biodegradability ratio recorded for the 6 blends of LDPE/Manihot esculenta; the higher the percentage of starch in the blend, the greater the degradation. 


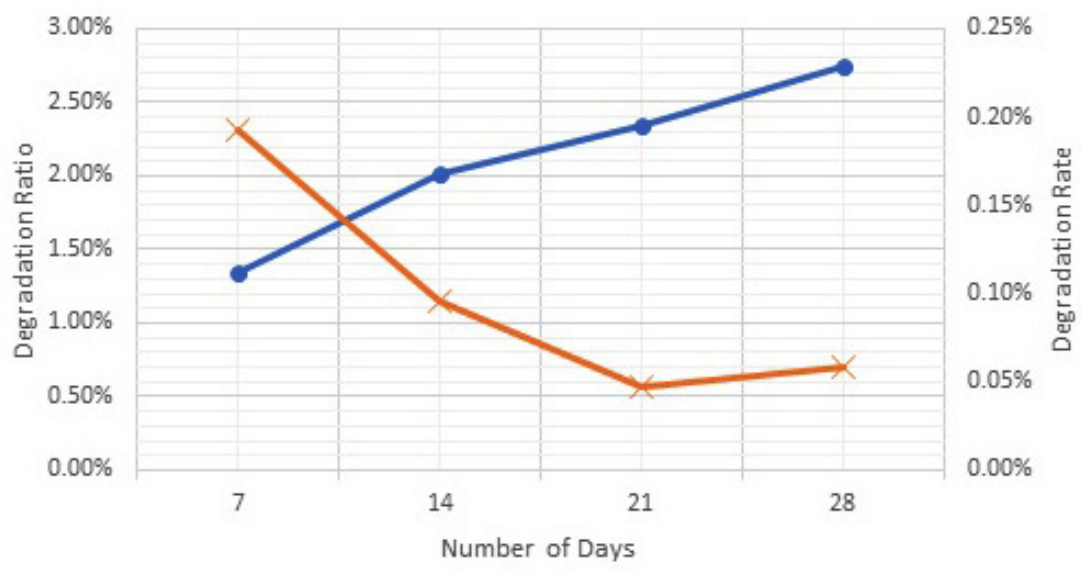

$\longrightarrow 5$ CaS Degradation Ratio $\quad 5$ CaS Degradation Rate

Figure 2. Biodegradation ratios and rate of LDPE-Manihot esculenta Blend Sample 5 CaS over 28 days

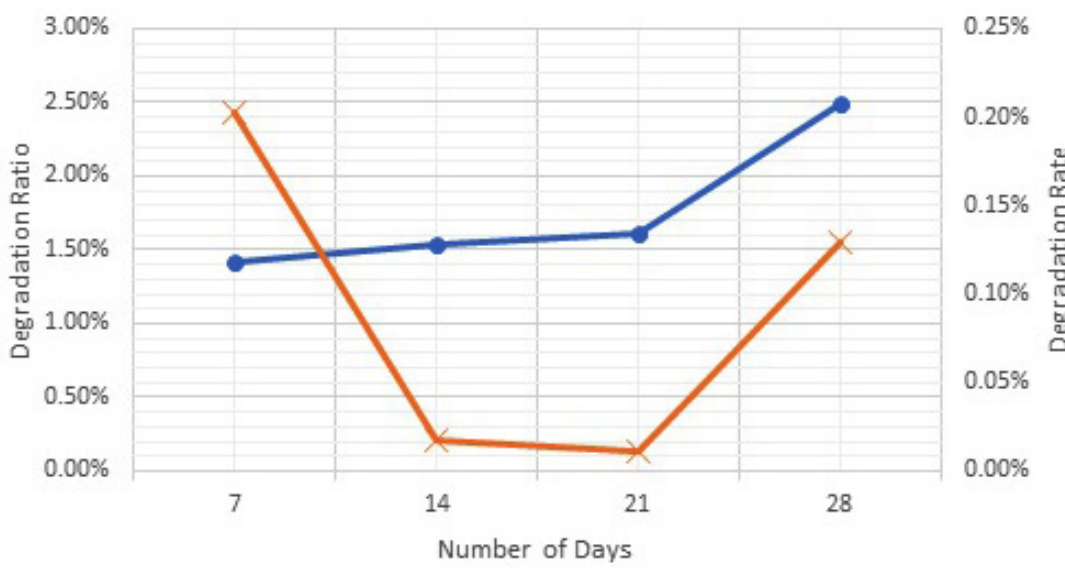

10 CaS Degradation Ratio $\quad$ —10 CaS Degradation Rate

Figure 3. Biodegradation ratios and rate of LDPE-Manihot esculenta Blend Sample 10 CaS over 28 days

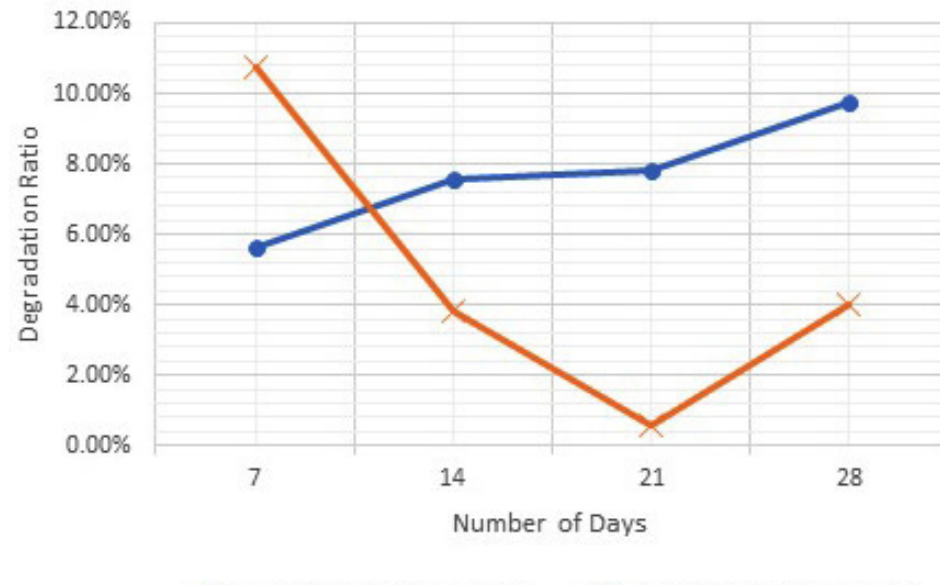

Figure 4. Biodegradation ratios and rate of LDPE-Manihot esculenta Blend Sample 15 CaS over 28 days 


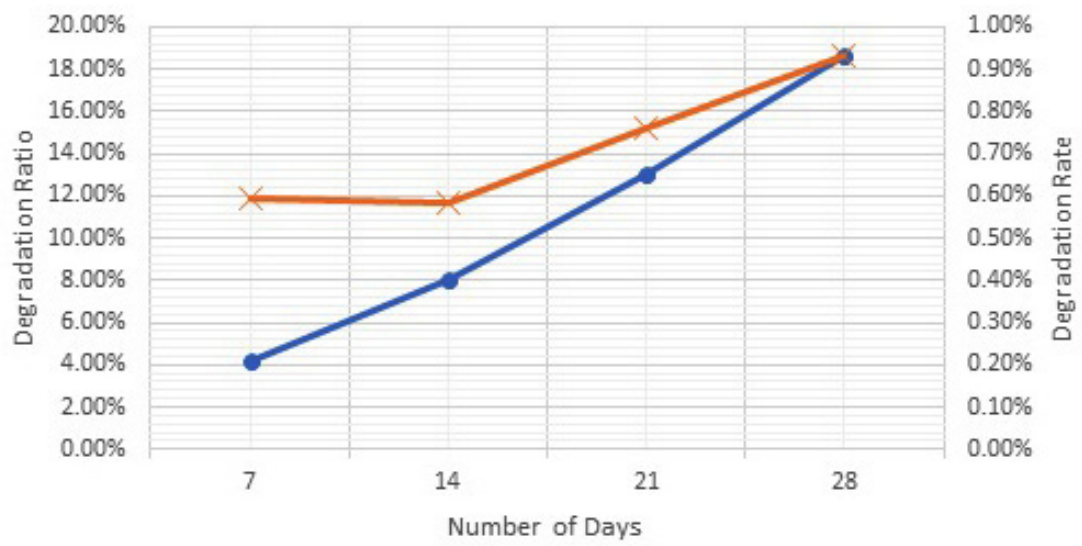

-20 CaS Degradation Ratio $\quad 20$ CaS Degradation Rate

Figure 5. Biodegradation ratios and rate of LDPE-Manihot esculenta Blend Sample 20 CaS over 28 days

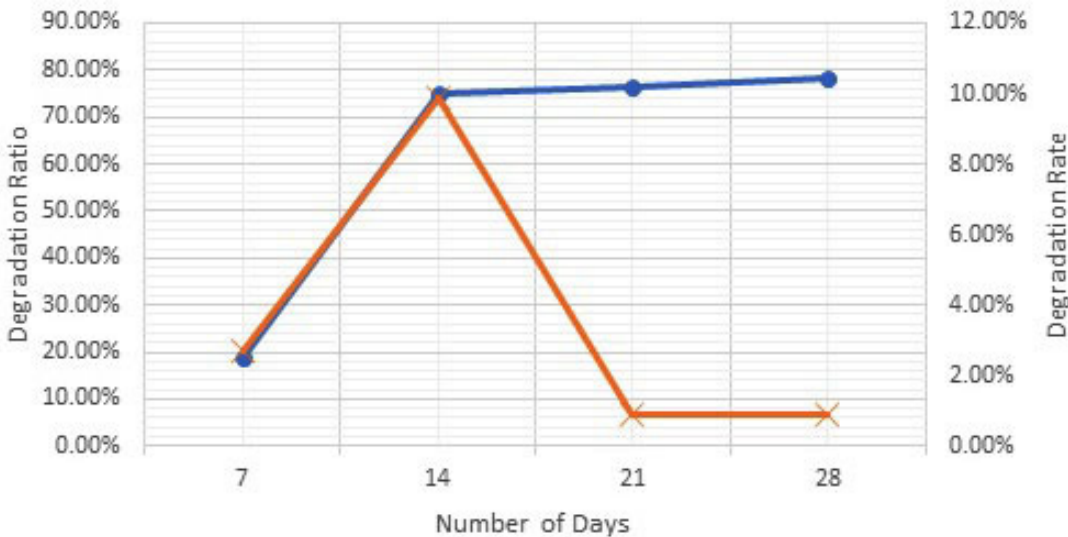

-40 CaS Degradation Ratio ب40 CaS Degradation Rate

Figure 6. Biodegradation ratios and rate of LDPE-Manihot esculenta Blend Sample 40 CaS over 28 days
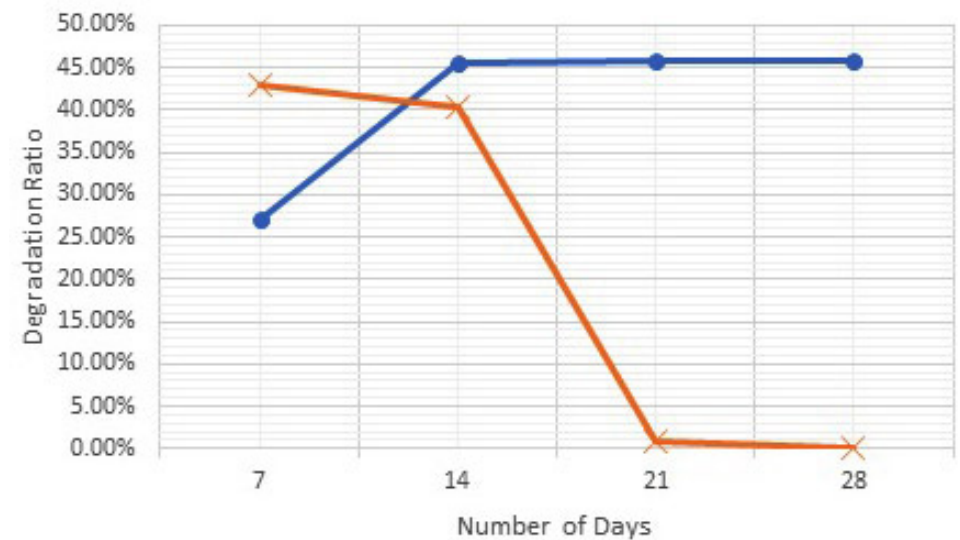

$4.50 \%$

$4.00 \%$

$3.50 \%$

$3.00 \%$ 芴

$2.50 \%$

$2.00 \%$

$1.50 \%$

$1.00 \%$

$0.50 \%$

$0.00 \%$

Number of Days

-50 CaS Degradation Ratio

Figure 7. Biodegradation ratios and rate of LDPE-Manihot esculenta Blend Sample 50 CaS over 28 days 


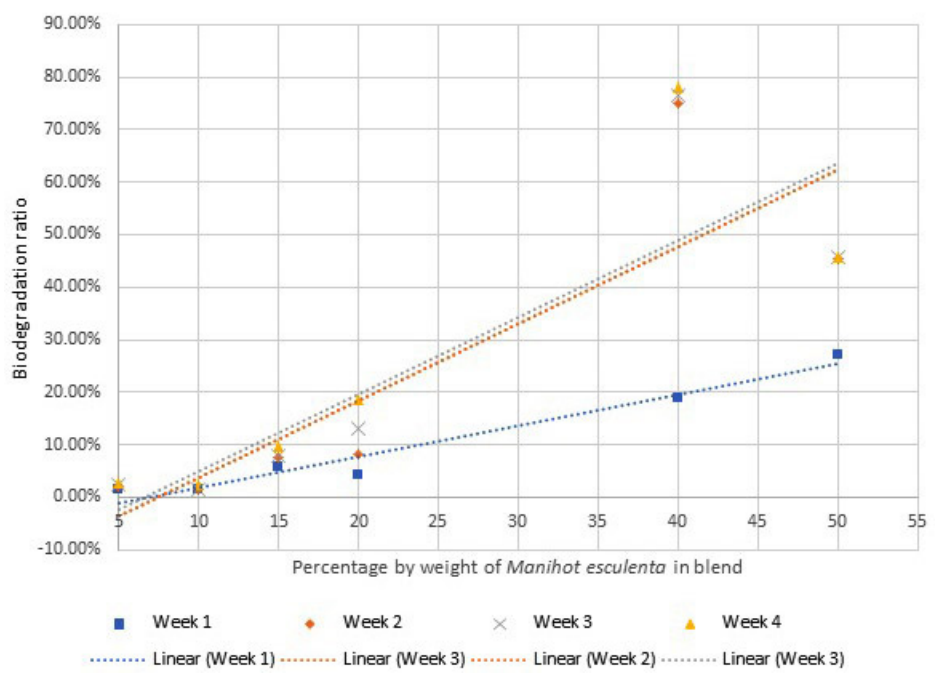

Figure 8. Linear relationship between biodegradability and blend ratio of LDPE-Manihot esculenta

The highest biodegradation ratios were recorded for $40 \mathrm{CaS}$ and $50 \mathrm{CaS}$; between $18 \%$ and $79 \%$ while $5 \mathrm{CaS}$ and $10 \mathrm{CaS}$ had the lowest degradation ratios; less than $3 \%$ throughout the four weeks. This is possibly due to the high LDPE content in the $5 \mathrm{CaS}$ and $10 \mathrm{CaS}$ samples. According to Figure 5, $20 \mathrm{CaS}$ had the most consistent and fairly regular degradation ratios and degradation rate per day over the period of the study.

\section{CONCLUSION}

The results showed that the polymer blends with $80 \%$ LDPE (20 CaS) by weight had the most regular weight loss over the period of the study. Under the conditions the study was carried out, polymer blend $20 \mathrm{CaS}$ also had the steadiest rate of degradation. Hence, $80 \%$ LDPE (wt.\%) blended with Manihot esculenta starch is the optimal ratio with regard to the degradability of biopolymer in sandy-loam soil. The biodegradation results also show a linear relationship between the percentage weight of starch in a biopolymer blend and the biodegradability of the biopolymer. All formulated blends have proven to be biodegradable and can be selected for various applications based on the required properties.

\section{REFERENCES}

1. Abbott, A. P., Abolibda, T. Z., Davis, S. J., Emmerling, F., Lourdin, D., Leroyd, E. and Wise, W. R. (2014). Glycol based plasticisers for salt modified starch. RSC Adv., 4, 40421-40427.
2. Akinpelu, A.O., Amamgbo, L. E.F., Olojede, A.O., Oyekale, A.S. (2011). Health Implications of Cassava Production and Consumption. Journal of Agriculture and Social Research, 11(1).

3. Andrej K. (2012), Biodegradable Polymers and Plastics, Innovative Value Chain Development for Sustainable Plastics in Central Europe (PLASTiCE), www.plastice.org

4. Axel S. (2009), Cotton Linters: An Alternative Cellulosic Raw Material, Macromolecular Symposia, 280(1), 45-53

5. Barnes D.K.A., Galgani F., Thompson R.C. \& Barlaz M. (2009) Accumulation and Fragmentation of Plastic Debris in Global Environments. Philosophical Transactions of the Royal Society B, 364:1985-1998. (doi:10.1098/rstb.2008.0205)

6. Cho, H. S., Moon, H. S., Kim, M., Nam, K., \& Kim, J. Y. (2011). Biodegradability and biodegradation rate of poly(caprolactone)-starch blend and poly (butylene succinate) biodegradable polymer under aerobic and anaerobic environment. Waste Management, 31(3), 475-480. https://doi. org/10.1016/j.wasman.2010.10.029

7. D'Alessandro, N. (2014). 22 Facts about Plastic Pollution. Retrieved March 24, 2018, from https://www.ecowatch.com/22-facts-about-plastic-pollution-and-10-things-we-can-do-aboutit-1881885971.html

8. Derraik J.G.B. (2002), The Pollution of the Marine Environment by Plastic Debris: A Review, Marine Pollution Bulletin, 44, 842-852.

9. Dong A.J., Zhang, J.W., Jiang K. and Deng L.D. (2008), "Characterization and in-vitro Degradation of Poly (octadecanoic anhydride), J. Mater Sci., 19, $39-46$.

10. Egesi, C., Mbanaso, E., Ogbe, F., Okogbenin, E. and Fregene, M. (2006). Development of cassava 
varieties with high value root quality through induced mutations and marker-aided breeding. NRCRI, Umudike Annual Report. 2-6

11. FAO, (2008). Corporate Document Repository. [Online]. The impact of HIV/AIDS on the agricultural sector. www.fao.org/DOCREP/005/Y4636E/ y4636e $05 . h$ tm

12. Farrin J (2005) Biodegradable plastics from natural resources. Institute of Technology, Rochester

13. Garrison, T. F., Murawski, A and Quirino, R. L. (2016) Bio-Based Polymers with Potential for Biodegradability. Polymers, 8(7), 26

14. Gilpin R., Wagel D. \& Solch J. (2003) Production, Distribution and Fate of Polycholorinated dibenzop-dioxins, Dibenzofurans and Related Organohalogens in the Environment. In Dioxins and health (eds A. Schecter \& T. Gasiewicz), 2nd edn. Hoboken, NJ: John Wiley \& Sons Inc.

15. Gregory M.R. (2009) Environmental Implications of Plastic Debris in Marine Settings Entanglement, Ingestion, Smothering, Hangers-on, Hitch-hiking and Alien Invasions. Phil. Trans. R. Soc. B 364, 2013-2025. (doi:10.1098/rstb.2008.0265)

16. Hopewell J, Dvorak R, Kosior E. (2009) Plastics Recycling: Challenges and Opportunities. Philosophical Transactions of the Royal Society B: Biological Sciences. 364(1526), 2115-2126. doi:10.1098/rstb.2008.0311.

17. Johnsson, N., \& Steuer, F. (2018). Bioplastic material from microalgae: Extraction of starch and PHA from microalgae to create a bioplastic material.

18. Ladeira T., Souza H. and Pena R. (2013), Characterization of the roots and starches of three cassava cultivars, International Journal of Agricultural Science Research, 2(1), 12-20

19. Leonel M (2007). Analysis of the shape and size of starch grains from different botanical species. Ciênc. Tecnol. Aliment., 27(3): 579-588.

20. Mahalakshmi V. and Andrew S.N. (2012), Assessment of Physicochemically treated plastic by fungi, Annals of Biological Research 3(9):4374-4381
21. Makhtar, N. S. M., Rais, M. F. M., Rodhi, M. N. M., Bujang, N., Musa, M., \& Hamid, K. H. K. (2013). Tacca leontopetaloides starch: New sources starch for biodegradable plastic. Procedia Engineering, 68, 385-391. doi.org/10.1016/j.proeng.2013.12.196

22. Maryam H.Y. and Hadi S.A. (2016), Synthesis, Characterization and Cytotoxicity Study of Poly (ethylene glycol) - HexamethyleneSebacamide Biopolymer, The Iraqi Journal for Mechanical and Material Engineering, Special Vol, Part II.

23. Mostafa N.A., Awatef A.F., Hala M.A. and Aghareed M.T. (2018), Production of Biodegradable Plastic from Agricultural Wastes, Arabian Journal of Chemistry. (11), 546-553

24. Norbert M.B., Herman F.M, Norman G.G. (1968), Encyclopaedia of polymer science and technology: plastics, resins, rubbers, fibres, vol 9, Wiley, New York, p 275

25. Sigler M. (2014). The Effects of Plastic Pollution on Aquatic Wildlife: Current Situations and Future Solutions. Water, Air and Soil Pollution, 225(2184), 1-9 (DOI 10.1007/s11270-014-2184-6)

26. Stevens, E.S. (2002) Green Plastics: An Introduction to the New Science of Biodegradable Plastics. Princeton, NJ: Princeton University Press,

27. Westblad C., Levendis Y.A., Richter H., Howard J.B. \& Carlson J (2002), A Study on Toxic Organic Emissions from Batch Combustion of Styrene, Chemosphere, 49(4), 395-412 (https://doi. org/10.1016/S0045-6535(02)00311-9)

28. Wroblewska-Krepsztul J., Rydzkowski T., Borowski G., Szczypinski M.M., Klepka T., Thakur V.K., 2018. Recent progress in biodegradable polymers and nanocomposite-based packaging materials for sustainable environment. International Journal of Polymer Analysis and Characterization, 23(4), 383-395.

29. Yang J., Webb, A.R., Pickerill, S.J., Hageman G. and Ameer, G.A. (2006) Synthesis and Evaluation of Poly (diolcitrate) Biodegradable Elastomers. Biomaterials, 27, pp. 1889-1898. 